\title{
Mechanical Properties of Methane Hydrate Interbedded with Clayey Sediments
}

\author{
Yanghui Li, Qi Wu, Peng Wu, Weiguo Liu* \\ Key Laboratory of Ocean Energy Utilization and Energy Conservation of Ministry of Education, Dalian University of Technology, Dalian, P. R. \\ China \\ Email address: \\ liy@dlut.edu.cn(YanghuiLi), 1373939696@qq.com(Qi Wu),1019659203@qq.com(Peng Wu),liuwg@dlut.edu.cn(Weiguo Liu) \\ ${ }^{*}$ Corresponding author
}

\section{To cite this article:}

Yanghui Li, Qi Wu, Peng Wu, Weiguo Liu. Mechanical Properties of Methane Hydrate Interbedded with Clayey Sediments. Journal of Energy and Natural Resources. Vol. 7, No. 1, 2018, pp. 24-31. doi: 10.11648/j.jenr.20180701.14

Received: March 13, 2018; Accepted: April 17, 2018; Published: April 27, 2018

\begin{abstract}
Methane hydrate was found interbedded with clayey sediments in permafrost regions, and it is important to study the mechanical properties of the hydrate-bearing layers to assess the stability during hydrate exploitation. In this paper, a series of triaxial experiments was conducted on hydrate-bearing sediments which were prepared by compacting hydrate layer (A), kaolin clay layer $(\mathrm{B})$ and the mixture of hydrate and kaolin clay layer $(\mathrm{C})$ in different orders $(\mathrm{ABC}, \mathrm{ACB}, \mathrm{CAB})$ and with different tilted angles $\left(0^{\circ}, 10^{\circ}, 25^{\circ}\right)$ in a specially designed mold device. The volume of methane hydrate was $40 \%$ of the whole volume of the sample. The triaxial experiments were conducted under the confining pressure of $5 \mathrm{MPa}$, temperature of $-10^{\circ} \mathrm{C}$ and strain rate of $1 \% / \mathrm{min}$. The results indicated that the maximum deviator stress of the sediments $(\mathrm{ABC})$ increased with the increasing of the tilted angle of layers, however, there was an opposite trend with the sediments $(\mathrm{CAB})$. And the maximum deviator stress of the sediments (ACB) increased first and then decreased. The failure strength achieved maximum when the hydrate layer was in the center of the sediments.
\end{abstract}

Keywords: Methane Hydrate, Mechanical Properties, Tilted Angles, Stratified

\section{Introduction}

Energy is the foundation of all creatures' activities, and the survival of biological, social development is inseparable from the appearance of high quality energy and advanced energy using. Energy sources can change rapidly, depending on the level of the development of civilization.

With the increasing depletion of traditional fossil energy and the environmental pollution caused by burning fossil fuels, natural gas hydrate is regarded as potential alternative clean energy receiving worldwide extensive attention because of its huge reserves and high energy density [1]. Natural gas hydrate distributes all over the world, mainly in the permafrost, and deep water sediments of the sea or the continental margin [2, 3 and 4]. Many regions of gas hydrate deposits were found in the world, such as Mackenzie area in Canada and Qinghai-Tibet Plateau, the Qilian Mountain tundra, the Greater Xing'an Mountains in China and so on [5] Potential reserves of hydrated gas are over $1.5 \times 1016 \mathrm{~m} 3$ [6].
Natural gas hydrates are solid, non-stoichiometric compounds of small gas molecules and water. Most of the gas molecules are methane molecules so the methane hydrate was used to instead of natural gas hydrate to do research in the laboratory. Natural gas hydrates form when the constituents come into contact at low temperature and high pressure [4]. They form in the reservoir supported by the cemented or skeletal form which is different from petroleum, natural gas and other resources [2, 13]. As a metastable substance, the rise of the temperature or the reduction of pore pressure possibly causes dissociation of hydrate [3, 4]. While drilling for exploration and exploitation, temperature and/or pressure changes can modify the gas hydrate equilibrium conditions and induce gas production. Gas may alter significantly the mechanical strength of the marine sediments [7], which can initiate landslides on the slope and rise, then lead to tsunami and 
methane leak which may influence the global climate $[8,9]$. Therefore, a comprehensive analysis about the stability of the gas hydrate deposits should be studied to fully grasp inherent mechanism of it to avoid the damage of the climate caused by the dissociation of the gas hydrate. These works must be done welly before the commercial exploitation of natural gas hydrate resource.

Many scholars have been studying the gas hydrate in recent years due to its potential values. Hyodo et al. did a series of triaxial compression test on methane hydrate-bearing sediments and proved that the strength of gas hydrate deposits increased with the increasing of confining pressure [11]. Miyazaki et al. did a series of triaxial compression tests for methane hydrate-bearing sediments and discovered that the effective confining pressure would limit the lateral deformation of sediments [12]. Priest et al. used a dedicated gas hydrate resonant column (GHRC) to research the relationship between the velocities of vibration wave and pore saturation of hydrate [13]. Some uniaxial compression tests have been carried out under a series of low temperature conditions $[14,15]$. But there are few studies on mechanical properties of methane hydrate interbedded with clayey sediments, which were found in areas where gas hydrate existed. In this paper, a series of triaxial shear tests were carried out to study the mechanicals characteristics of methane hydrate interbedded with clayey sediments using the triaxial test system, and the test samples were made by a specially designed mold device.

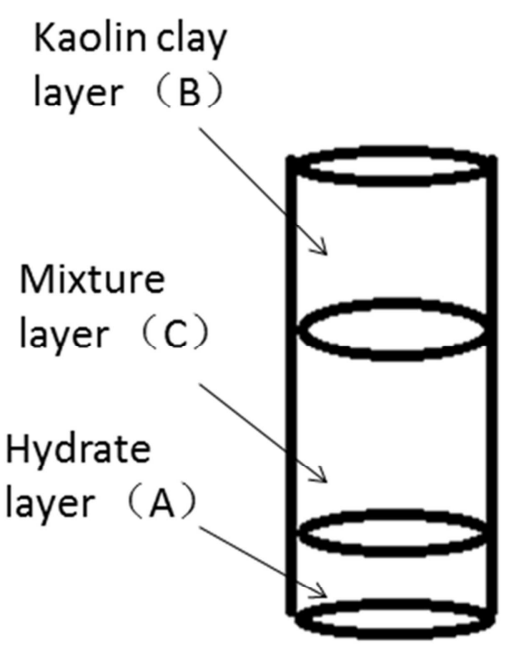

\section{Experimental Methods}

\subsection{Sample Preparation}

In this paper, the sample preparation process was almost as same as the previous work [16]. The particle size of about $250 \mu \mathrm{m}$ of ice powder particles was made firstly by ice crushed machine and the sieve, then put them into stainless steel reactor and rejected into the chamber with methane gas of $10 \mathrm{MPa}$ at the temperature of $-10^{\circ} \mathrm{C}$ and kept the reactor at the temperature of $-10^{\circ} \mathrm{C}$ for more than 48 hours to generate the methane hydrate. Next, the prepared mold and pressure crystallization device were placed into a cold storage room $\left(-10^{\circ} \mathrm{C}\right)$ to be cooled to prevent hydrate dissociation on mold-pressure process due to the higher temperature, and kaolin clay was under the same cold condition $\left(-10^{\circ} \mathrm{C}\right)$. Finally, the needed methane hydrate and kaolin clay were weighed which kept the volume of methane hydrate be $40 \%$ of the whole volume of the sample. The difference from the previous work is that each half of methane hydrate and kaolin clay were got and then mixed. Hydrate (A), kaolin clay (B) and the mixture of hydrate and kaolin clay (C) were put separately in the mold with different tilted angles $\left(0^{\circ}, 10^{\circ}\right.$, $\left.25^{\circ}\right)$ under the load conditions $(10 \mathrm{MPa})$ and be axially pressed into the desired size $(50 \mathrm{~mm} \times 100 \mathrm{~mm})$. As showed in Figure 1, hydrate lay was in the top of the sediment, mixture layer was in the center of the sediment and kaolin clay layer was in the bottom of the sediment. This kind of sample was marked as ACB order. The samples which were in order of $\mathrm{ABC}, \mathrm{CAB}$ had been prepared in the same way.

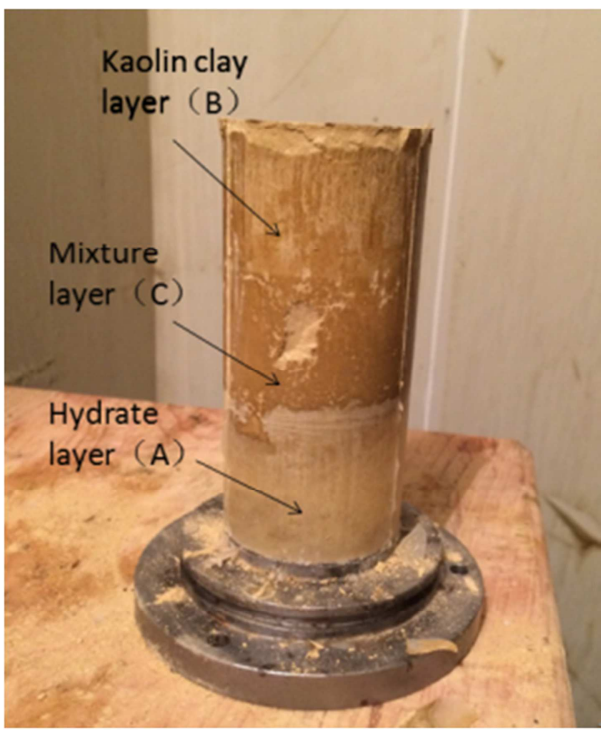

Figure 1. The sample in order of $A C B$ with the angle of $0^{\circ}$.

Three kinds of cylindrical wooden $\operatorname{rod}(50 \mathrm{~mm} \times 200 \mathrm{~mm})$ with a tilted angle top respectively $\left(0^{\circ}, 10^{\circ}, 25^{\circ}\right)$ were used to make the samples with different tilted angle of layers.

\subsection{Testing Apparatus}

Figure 2 shows the schematic diagram of the triaxial apparatus used in this study. The triaxial apparatus is composed of axial compression system, computer control system, temperature system and confining pressure servo system. 


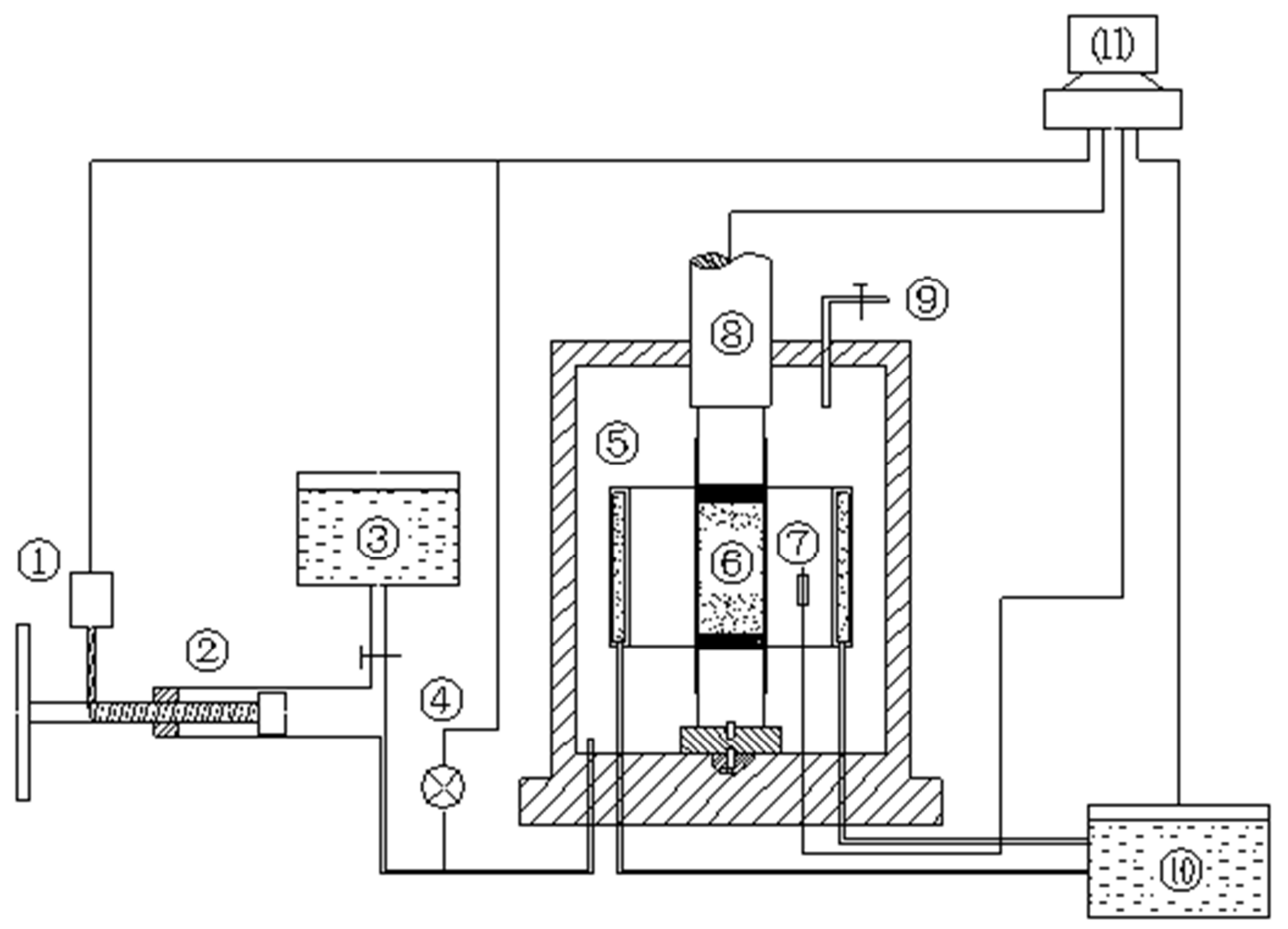

Figure 2. The schematic diagram of triaxial testing system.

1 Stepping motor, 2 Pump, 3 Hydraulic oil tank, 4 Pressure gauge, 5 Heat exchanger, 6 Sample, 7 Thermocouple, 8 Load cell, 9 Air pressure line, 10 Thermostatic bath, 11 Computer.

\subsection{Testing Procedures and Experimental Conditions}

What needed to do is that matching two end caps at the top and bottom of the sample respectively and then wrapping it with a rubber membrane which could prevent the hydraulic oil flowing into the sample, before put the sample into the confining chamber. It should be as shorter as 5 mins possibly in order to reduce hydrates dissociation when the sample was shifted from mold into the pressure chamber. In addition, the whole testing procedures were accomplished in a cold storage room $\left(-10^{\circ} \mathrm{C}\right)$. The Kaolin volume ratio of all samples is $60 \%$ and the saturation of methane hydrate is $30 \%$. Experimental conditions were shown in Table 1.

Table 1. Experimental conditions of triaxial compression tests.

\begin{tabular}{lllll}
\hline Order & Tilted angle & Temperatur ${ }^{\circ} \mathbf{C}$ & Confining pressure (MPa) & Strain rate (/min) \\
\hline \multirow{2}{*}{$\mathrm{ACB}$} & $0^{\circ}$ & & & $1.0 \%$ \\
& $10^{\circ}$ & -10 & 5 & \\
& $25^{\circ}$ & & & \\
$\mathrm{CAB}$ & $0^{\circ}$ & -10 & 5 & $1.0 \%$ \\
& $10^{\circ}$ & & & $1.0 \%$ \\
$\mathrm{ABC}$ & $25^{\circ}$ & -10 & 5 & \\
& $0^{\circ}$ & $10^{\circ}$ & & \\
\hline
\end{tabular}

\section{Discussions and Results}

The methane hydrate interbedded with clayey sediments with the layers of angle 0 degree showed plastic deformation during the triaxial compression test. After the test, the medium of the cylinder sample protruded in lateral and its profile looked like a drum. The samples with the layers of tilted angle 10 degree and 25 degree also showed plastic deformation but it was not obvious, and slippage occurred in the interface. The influencing factors on mechanical properties of methane hydrate interbedded with clayey sediments were investigated in this paper. 


\subsection{Effect of the Layer Order}

The needed Kaolin clay and methane hydrate were uniform mixing in the previous work [17]. However there is methane hydrate interbedded with clayey existed in the nature. In this part, a series of triaxial experiments was conducted to make it clear how the order taken effect when methane hydrate-bearing sediments were under triaxial compression.

Figure 3 indicates the relationship between deviator stress and axial strain of sediments in different orders $(A B C, A C B$, $\mathrm{CAB}$ ). From Figure 3, it can be found that in the initial stage of the shear (axial strain of less than $0-1.0 \%$ ) the deviator stress of the sample increased linearly with the increasing of the axial strain, and there were some elastic properties during this phase. The sample axial deviator stress continued to increase when axial strain was increasing, but the rate of increasing gradually decreased. Then the sample elastic-plastic deformation occurred. The sample started to yield when the axial deviator stress reached a certain level. Related studies show that stress-strain curve of materials can be divided into three stages: quasi-elastic phase, hardening phase and the yield phase. These can be found in Figure 3 which means that the three stages of the stress-strain curve appeared in the methane hydrate interbedded with clayey sediments. The trend of the stress-strain curve was the same as it which was in the previous work [17] when the samples were made by uniformly mixing Kaolin clay and methane hydrate.

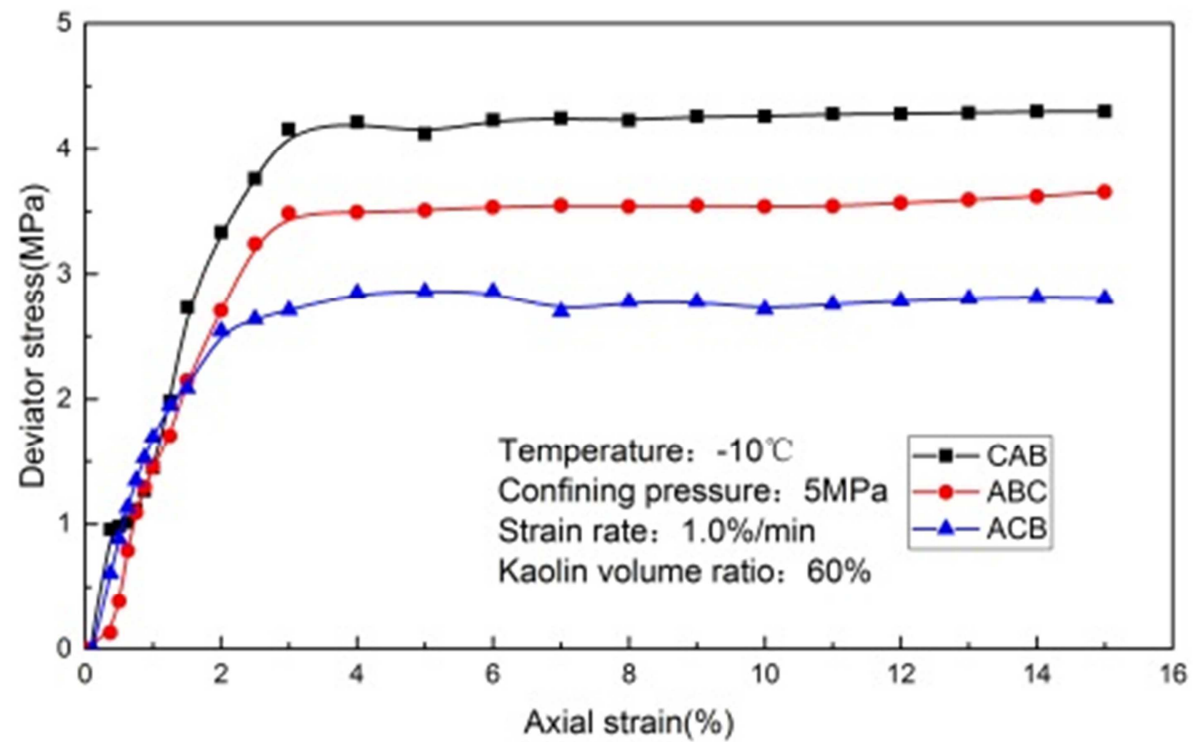

(a) Tilted angle of the layer $\left(0^{\circ}\right)$

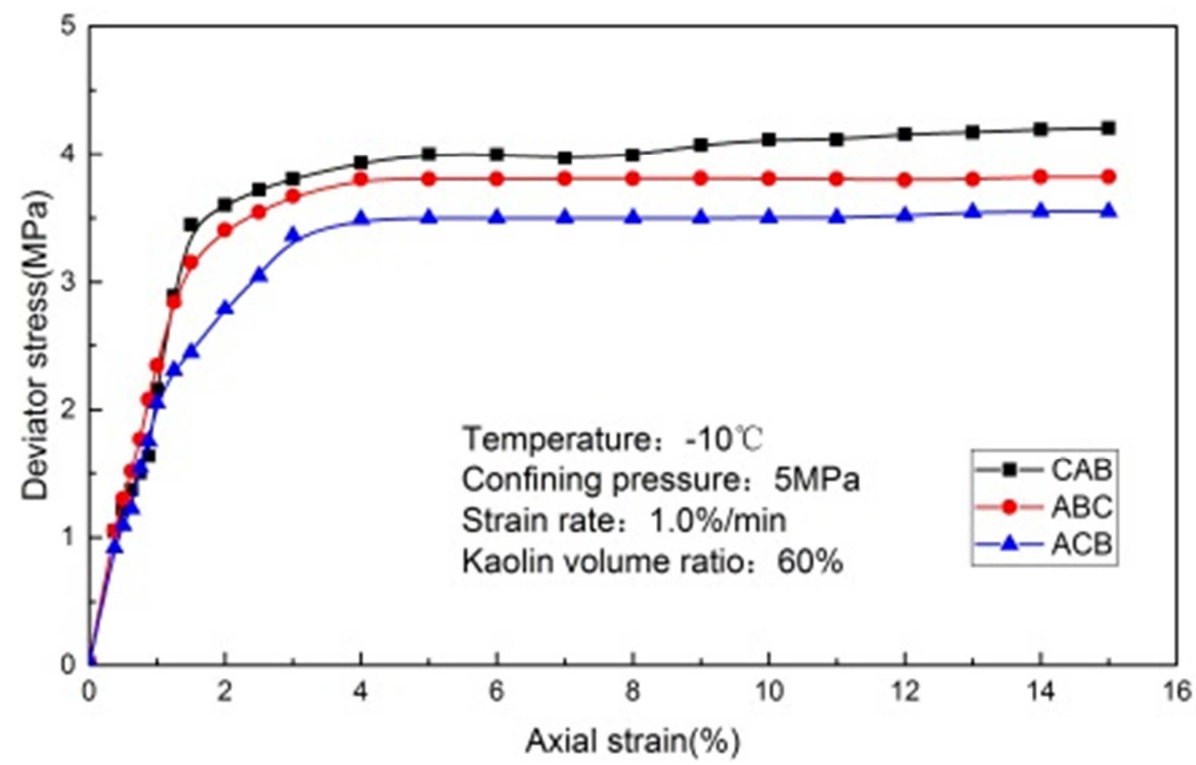

(b) Tilted angle of the layer $\left(10^{\circ}\right)$ 


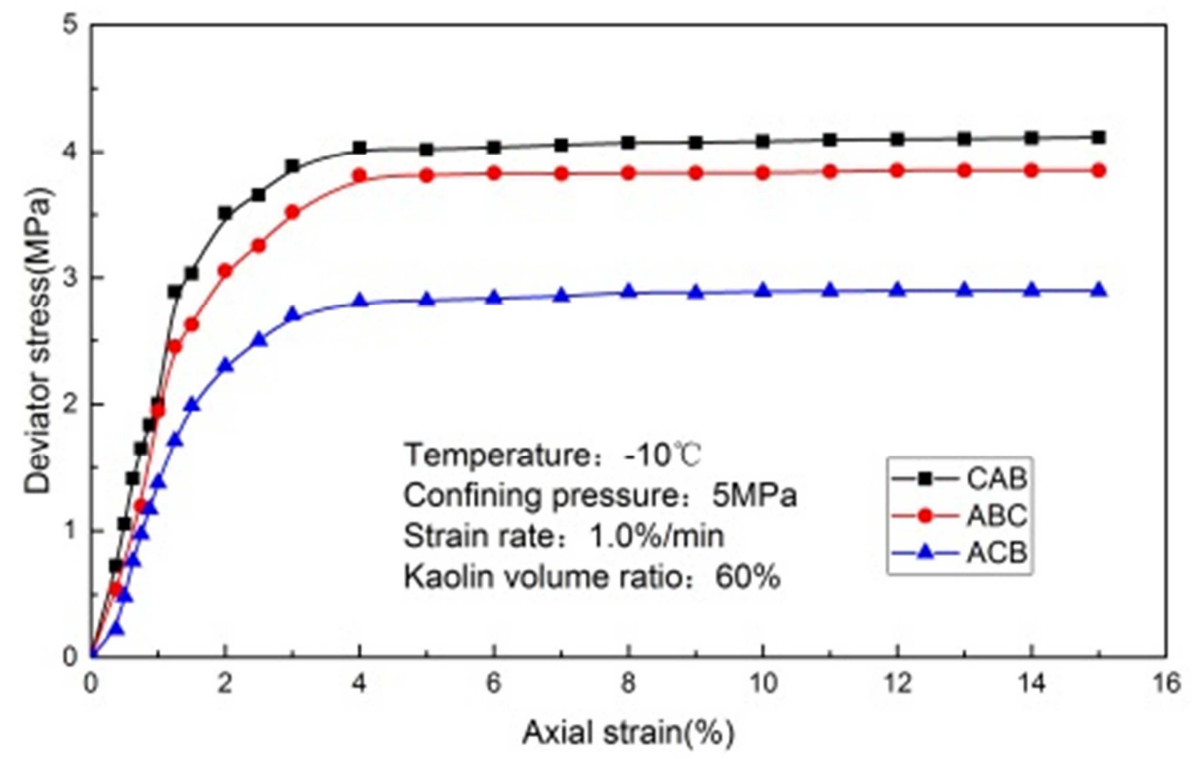

(c) Tilted angle of the layer $\left(25^{\circ}\right)$

Figure 3. Relationship between deviator stress and axial strain of sediments in different orders (ABC, $A C B, C A B)$.

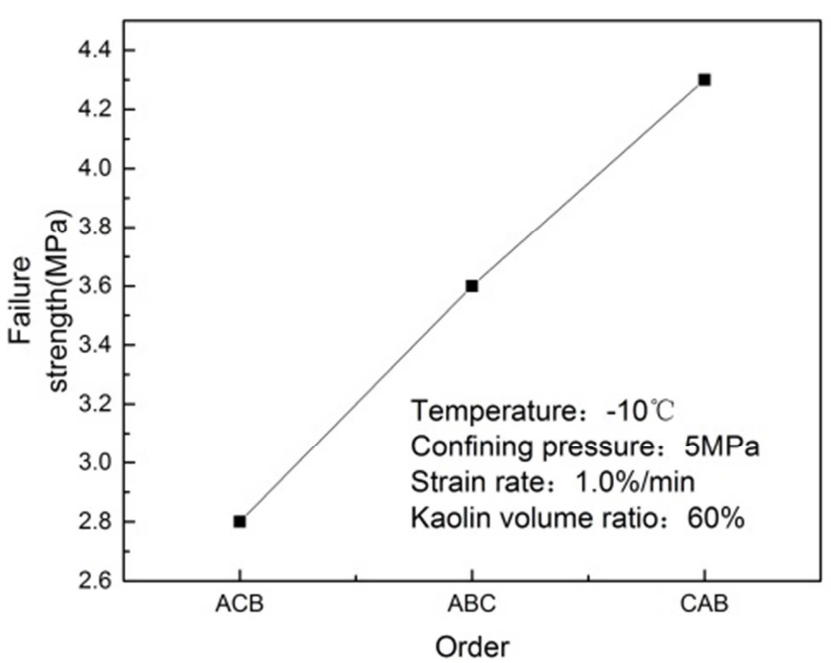

(a) Tilted angle of the layer $\left(0^{\circ}\right)$

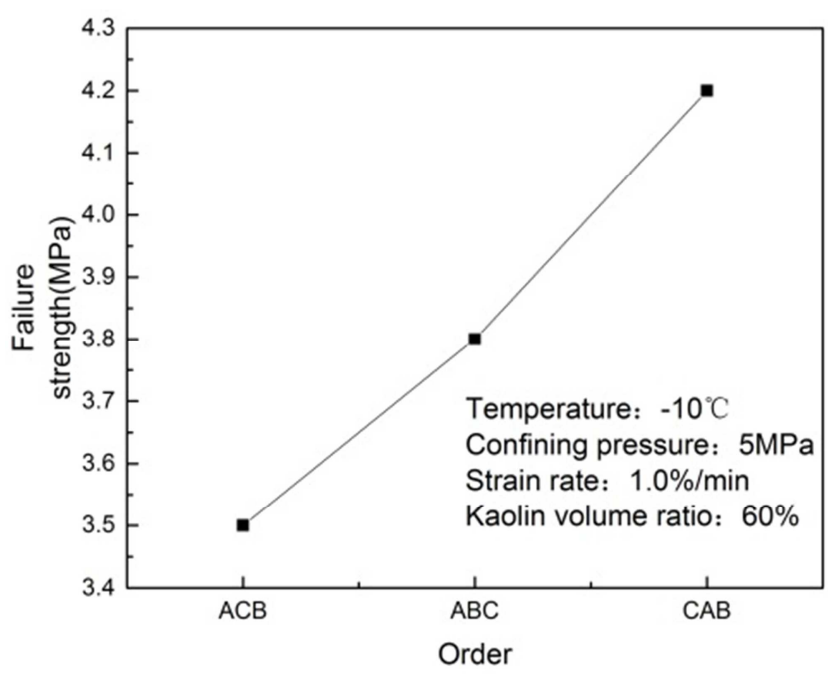

(b) Tilted angle of the layer $\left(10^{\circ}\right)$

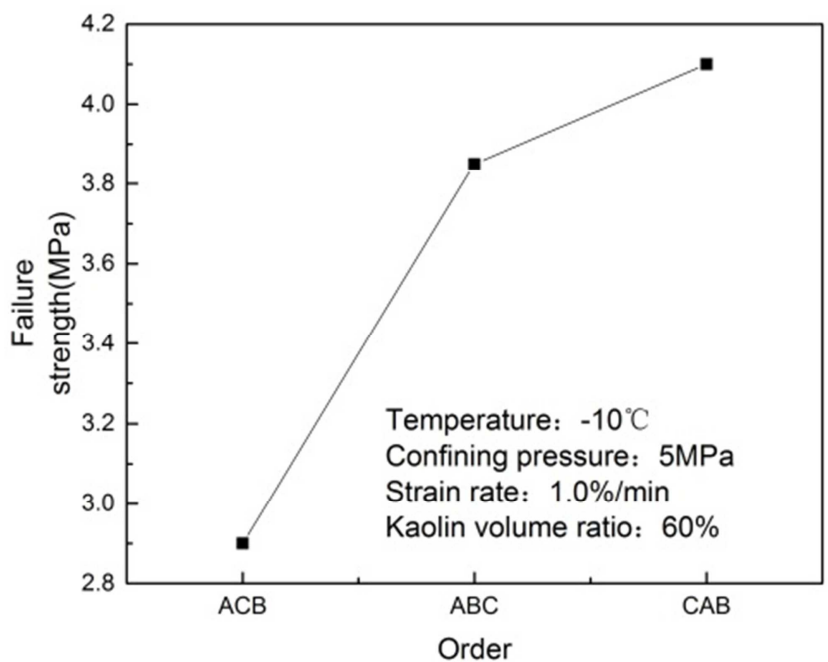

(c) Tilted angle of the layer $\left(25^{\circ}\right)$

Figure 4. Relationship between failure strength and the orders $(A B C, A C B$, $C A B)$.

The maximum deviator stress is defined as the peak value during the compression tests until the axial strain reaches $15 \%$, and it is also defined as failure strength of the sediment. Figure 4 indicates that failure strength of the sediment which was in order of $\mathrm{CAB}$ was bigger than that in order of $\mathrm{ABC}$, however, ABC's failure strength was bigger than ACB's whatever the tilted angle of layers was. The failure strength reached maximum, when the hydrate layer was in the center of the sediments. The minimum of failure strength occurred when the mixture layer was in the center of the sediments. The curve was approximate straight-line when the tilted angle of layers was small. 


\subsection{Effect of the Tilted Angle of Layers}

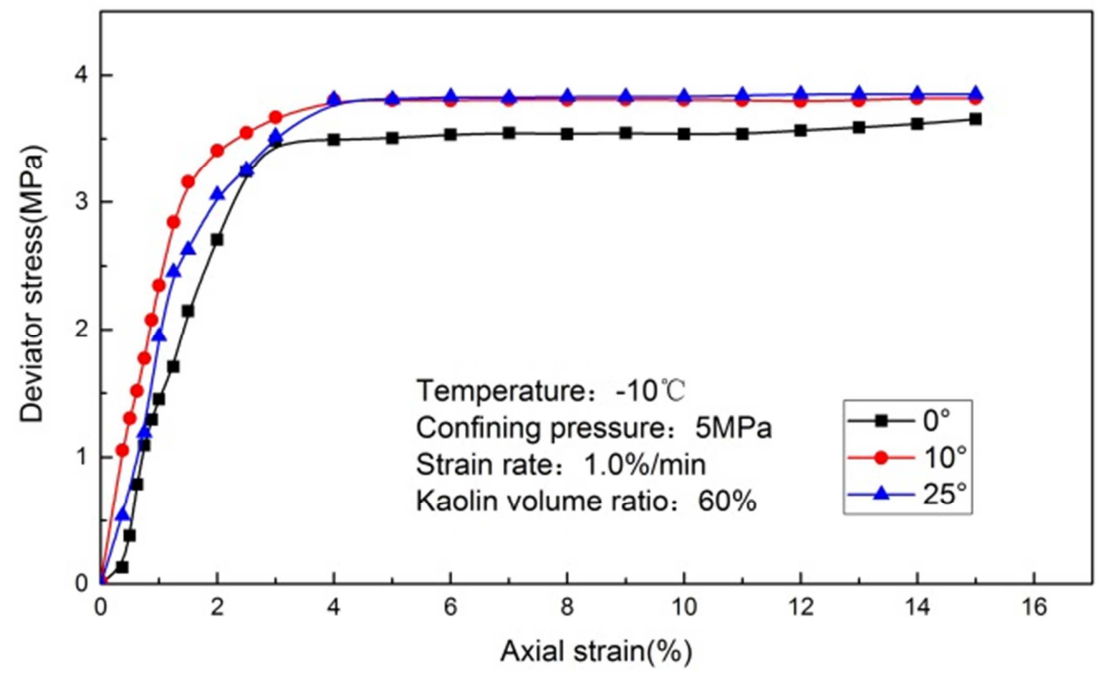

(a) The order $(\mathrm{ABC})$

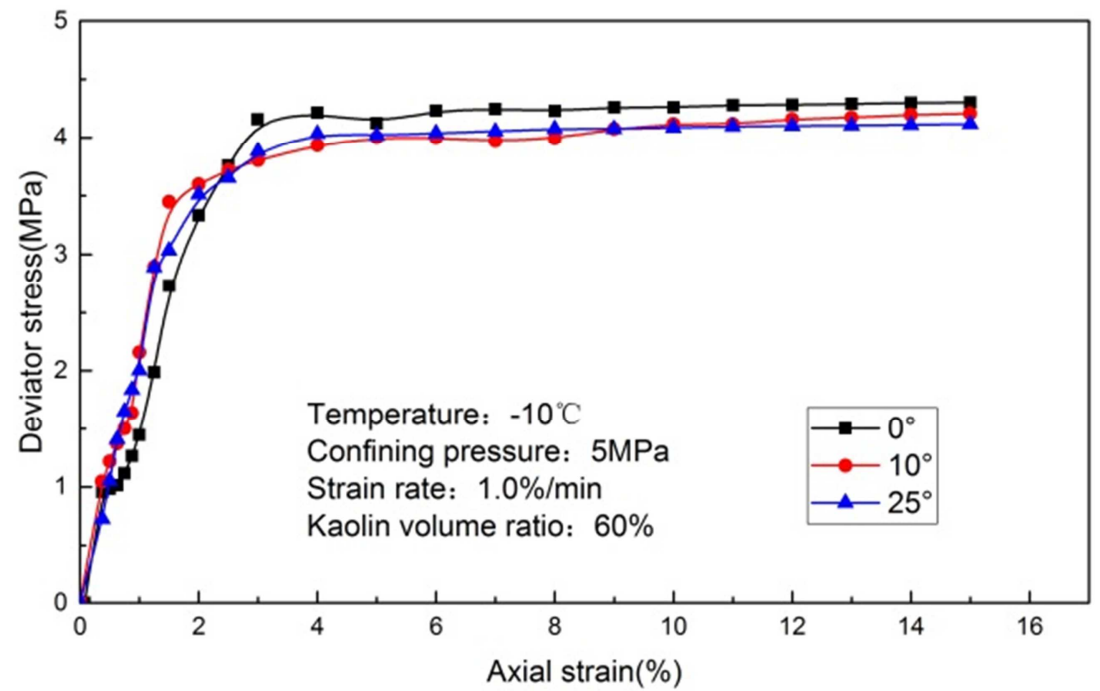

(b) The order (CAB)

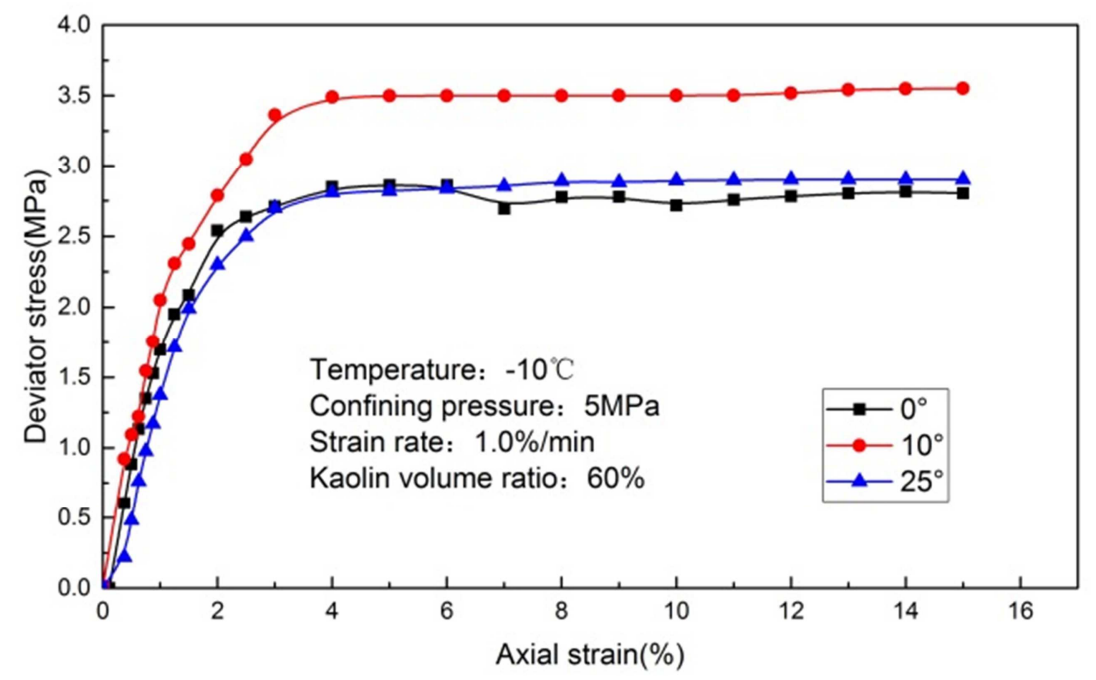

(c) The order (ACB)

Figure 5. Relationship between deviator stress and axial strain of sediments with different tilted angle of layers $\left(0^{\circ}, 10^{\circ}, 25^{\circ}\right)$. 


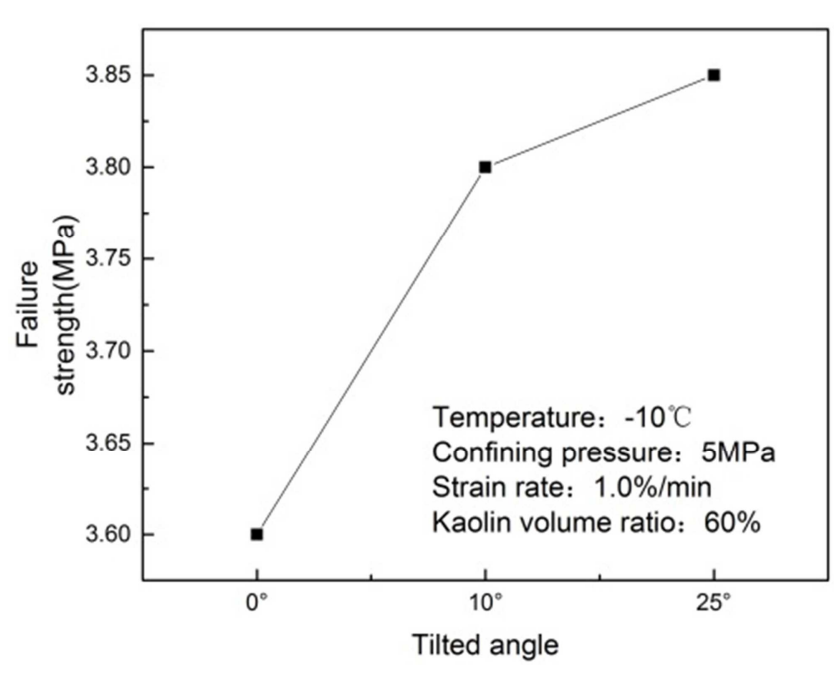

(a) The order $(\mathrm{ABC})$

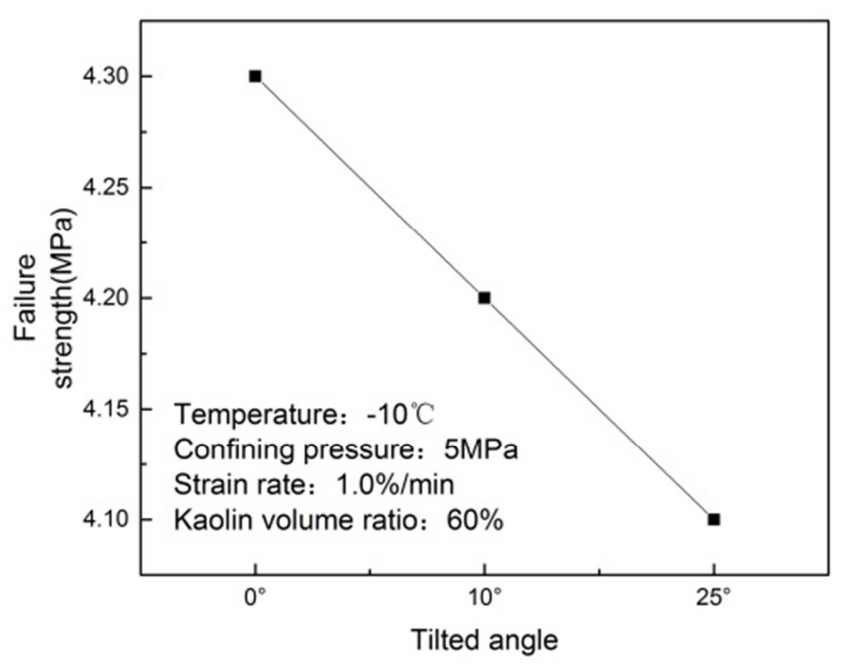

(b) The order (CAB)

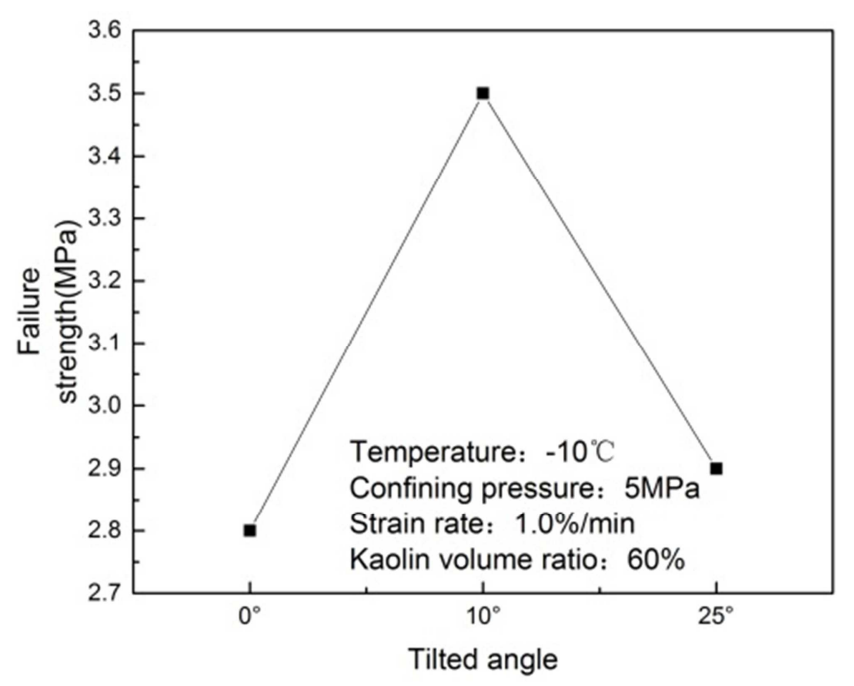

(c) The order (ACB)

Figure 6. Relationship between failure strength and the tilted angles $\left(0^{\circ}, 10^{\circ}\right.$, $\left.25^{\circ}\right)$.

Figure 5 shows relationship between deviator stress and axial strain of sediments with different tilted angle of layers $\left(0^{\circ}, 10^{\circ}, 25^{\circ}\right)$. It can be concluded that the trend of stress-strain curve was the same in one kind of order whatever the titled angle of layer was. Quasi-elastic phase, hardening phase and the yield phase could be found from figure 5. In order of $\mathrm{CAB}$, the maximum deviator stress of sediments with different tilted angle was almost $4.20 \mathrm{MPa}$, and it was almost $3.75 \mathrm{MPa}$ in order of ABC. However, the maximum deviator stress of sediments with tilted angle $10^{\circ}$ was obviously bigger than the other two kinds of sediments' in order of ACB. The increase of tilted angle could lead to the increase of the friction force of specimen's interface at a low angle stage because of the increasing contact area between two layers when the mixture layer was in the center of the sediments. But the bigger titled angle weakened its capability of resistance to deformation under the triaxial compression and resulted in slippage in the interface between two layers. Tilted angle can increase the failure strength of the sediment at a low stage when the mixture layer was in the center of the sediments according to these series of triaxial experiments.

Figure 6 presents the relationship between failure strength and the tilted angles $\left(0^{\circ}, 10^{\circ}, 25^{\circ}\right)$. It can be found that the maximum deviator stress of the sediments $(\mathrm{ABC})$ increased with the increasing of the tilted angle of layers in the range of small angles, however, the sediments (CAB) was contrary to the former. The failure strength increased first and then decreased when the sediments were in order of ACB.

In this part, the increasing of titled angle could enhance the friction force of specimen' interface at a low angle stage, but it was not appropriate for the other two orders (ABC, $\mathrm{CAB}$ ).

\section{Conclusions}

Based on the analysis and experimental results above, some conclusions can be drawn. With the same angle, the failure strength of the sediments in $\mathrm{ACB}, \mathrm{ABC}$ and $\mathrm{CAB}$ increased in turn. The strength achieved maximum when the hydrate layer was in the center of the sediments. The minimum of failure strength occurred when the mixture layer was in the center of the sediments. The strength-order curve was approximate straight-line when the tilted angle of layers was small. In the same order, there were different trends of the failure strength of the sediments when the tilted angle increased. The failure strength decreased with the angle increasing when the hydrate layer was in the center of the sediments; nevertheless it was adverse when the Kaolin clay layer was in the center of the sediments. The increase of tilted angle could lead to the increase of the friction force of specimen' $s$ interface at a low angle stage because of the increasing contact area between two layers when the mixture layer was in the center of the sediments.

Acknowledgements

This study was supported by the National Key Research and Development Program of China (Grant Nos. 2017YFC0307305, 2016YFC0304001 and 2017YFC0307705), and the National Natural Science 
Foundation of China (Grant Nos. 51676024 and 51509032).

\section{References}

[1] DEMIRBAS, Ayhan, et al. "Evaluation of natural gas hydrates as a future methane source." Petroleum Science and Technology, 2016, 34.13: 1204-1210.

[2] Priest J A, Rees E V L, Clayton C R I. "Influence of gas hydrate morphology on the seismic velocities of sands." Journal of Geophysical Research: Solid Earth, 2009, 114 (B11).

[3] Sloan E D. "Gas hydrates: Review of physical/chemical properties." Energy \& Fuels, 1998, 12 (2): 191-196.

[4] Sloan E D. "Fundamental principles and applications of natural gas hydrates." Nature, 2003, 426 (6964): 353-363.

[5] Li B, Sun Y, Guo W, et al. "The mechanism and verification analysis of permafrost-associated gas hydrate formation in the Qilian Mountain, Northwest China." Marine and Petroleum Geology, 2017, 86: 787-797.

[6] Makogon Y F, Holditch S A, Makogon T Y. "Natural gas-hydrates-A potential energy source for the $21 \mathrm{st}$ Century."Journal of Petroleum Science and Engineering, 2007, $56(1-3): 14-31$.

[7] Vanoudheusden E, Sultan N, Cochonat P. "Mechanical behaviour of unsaturated marine sediments: experimental and theoretical approache." Marine geology, 2004, 213 (1-4): 323-342.

[8] Dickens G R, O'Neil J R, Rea D K, et al. "Dissociation of oceanic methane hydrate as a cause of the carbon isotope excursion at the end of the Paleocene." Paleoceanography, 1995, 10 (6): 965-971.
[9] Brown H E, Holbrook W S, Hornbach M J, et al. "Slide structure and role of gas hydrate at the northern boundary of the Storegga Slide, offshore Norway." Marine geology, 2006, 229 (3): 179-186.

[10] Waite W F, Winters W J, Mason D H. "Methane hydrate formation in partially water-saturated Ottawa sand." American Mineralogist, 2004, 89 (8-9): 1202-1207.

[11] Hyodo M, Nakata Y, Yoshimoto N. "Basic research on the mechanical behavior of methane hydrate-sediments mixture."Soils and foundations, 2005; 45 (1): 75-85.

[12] Miyazaki K, Masui A, Aoki K, et al. "Strain-rate dependence of triaxial compressive strength of artificial methane-hydrate-bearing sediment." International Journal of Offshore and Polar Engineering, 2010, 20 (04).

[13] Priest J A, Best A I, Clayton C R I. "A laboratory investigation into the seismic velocities of methane gas hydrate - bearing sand." Journal of Geophysical Research: Solid Earth, 2005, 110 (B4).

[14] Stern L A, Kirby S H, Durham W B. "Peculiarities of methane clathrate hydrate formation and solid-state deformation, including possible superheating of water ice." Science, 1996, 273 (5283): 1843-1848.

[15] Durham W B, Kirby S H, Stern L A, et al. "The strength and rheology of methane clathrate hydrate." Journal of Geophysical Research: Solid Earth, 2003, 108 (B4).

[16] Li Y, Song Y, Yu F, et al. "Experimental study on mechanical properties of gas hydrate-bearing sediments using kaolin clay." China Ocean Engineering, 2011, 25 (1): 113-122.

[17] Liu W, Luo T, Li Y, et al. "Experimental study on the mechanical properties of sediments containing $\mathrm{CH} 4$ and $\mathrm{CO} 2$ hydrate mixtures." Journal of Natural Gas Science and Engineering, 2016, 32: 20-27. 